\title{
Participation in the Sharing Economy Revisited: The Role of Culture and Social Influence on Airbnb
}

\author{
Jieun Lee, Aybuke Nur Erdogan and Ilyoo Barry Hong *(D) \\ College of Business \& Economics, Chung-Ang University, 84 Heukseok-ro, Seoul 06974, Korea; \\ jlee114@cau.ac.kr (J.L.); aybuke.n.erdogan@gmail.com (A.N.E.) \\ * Correspondence: ihong@cau.ac.kr
}

check for updates

Citation: Lee, J.; Erdogan, A.N.; Hong, I.B. Participation in the Sharing Economy Revisited: The Role of Culture and Social Influence on Airbnb. Sustainability 2021, 13, 9980. https://doi.org/10.3390/su13179980

Academic Editors: Pier Luigi Sacco and Dimitrios Buhalis

Received: 5 August 2021

Accepted: 2 September 2021

Published: 6 September 2021

Publisher's Note: MDPI stays neutral with regard to jurisdictional claims in published maps and institutional affiliations.

Copyright: (c) 2021 by the authors. Licensee MDPI, Basel, Switzerland. This article is an open access article distributed under the terms and conditions of the Creative Commons Attribution (CC BY) license (https:/ / creativecommons.org/licenses/by/ $4.0 /)$.

\begin{abstract}
Despite a multitude of studies on the motivators of sharing economy participation, we understand little about how cultural and social drivers affect an individual's use of sharing services on an online platform. This paper examines the influence of cultural and social factors on a consumer's participation in a sharing economy. We used Hofstede's cultural dimensions theory and Ajzen's theory of planned behavior to formulate the research model to predict the behavioral intention to book an accommodation using the Airbnb platform. To test the model, an empirical study was conducted by collecting survey data on Amazon Mturk from 401 participants. Findings provide evidence that all the cultural dimensions except for masculinity were found to have significant relationship with attitude toward booking on Airbnb. Moreover, social influence has no significant effect on booking intention on Airbnb. We offered academic and practical implications and suggested future research directions based on our findings.
\end{abstract}

Keywords: sharing economy; Airbnb; national culture; accommodation sharing; cultural dimensions theory; theory of planned behavior

\section{Introduction}

The use of digital platforms to share under-utilized assets with unknown people has been steadily on the rise in recent years. According to Forbes [1], the global sharing economy is expected to mark USD 335 billion by 2025, up from USD 15 billion in 2015. The increasing use of information and communication technologies (ICTs), as well as the Internet, has significantly contributed to the emergence of various types of peer-to-peer sharing companies and services. Key industry sectors encouraging consumers to share rather than own include accommodations (Airbnb, Homestay), car rides (Uber, Lyft), office spaces (WeWork), kitchens (CloudKitchens), second-hand clothing (Thred Up, Dolap), and warehousing (Shbinder).

An accommodation sharing platform like Airbnb provides new lodging opportunities for consumers who have been relying on traditional facilities such as hotels, motels, and so forth. For that reason, its business success may largely be determined by lifestyles and cultural characteristics rather than technologies per se. According to Steenkamp et al. [2], culture plays a huge role in consumers' predisposition to adopt innovations and new services. In particular, it is essential to understand other cultures if one is to succeed in a global resource-sharing business [3]. Furthermore, a consumer's decision to book an accommodation on Airbnb would likely be affected by social influence as today's consumers increasingly depend on collective comments and recommendations posted on social networking sites.

Meanwhile, extant research has focused on identifying diverse drivers of sharing economy participation. These drivers include materialism [4], monetary motivations [5], environmental benefits [6], and social utility [7]. Nevertheless, we still understand little about the role of culture in collaborative consumption that denotes the shared use of a good or service by a group. While cultural values play a pivotal role in the widespread use 
of accommodation-sharing platforms, only a handful of studies $[3,4,8]$ have investigated the effect of cultural values on a consumer's intention to engage in a sharing economy transaction. Furthermore, even the findings of these studies conflict with one another, and they are not able to provide useful insights for overcoming cultural issues for global businesses operating a sharing platform.

The primary motivation of this study stems from the very need to fill this gap in the extant research. We aim to overcome the fundamental limitations of related studies by proposing a conceptual model from a cultural and social perspective and testing the conceptual model through an empirical analysis to ultimately provide implications that help to facilitate the accommodation sharing business. The purpose of this study is to uncover the role of cultural values and social influence in the formation of behavioral intention to engage in accommodation sharing on Airbnb. To this end, we will use the cultural dimensions theory [9] and the theory of planned behavior [10] to establish a research model to predict the intention to engage in a sharing service.

More specifically, this study has been undertaken to find answers to the following research questions (RQ).

RQ 1: How do cultural values affect consumers' attitude toward sharing economy participation? RQ 2: How does social influence contribute to the formation of consumers' intent to use sharing economy services?

The chief contribution of this study lies in clarifying the intricate relationships among cultural values, social influence, and accommodation sharing on Airbnb. It will help to better our understanding of the role of the culture and social influence in the formation of a consumer's intent to participate in a sharing economy. The findings of the study will provide useful implications for businesses to build a robust platform to permit a sharing transaction involving an accommodation.

The remainder of this paper is organized as follows. In Section 2, we review the related literature to identify research gaps, and propose research hypotheses and a conceptual model. In the following section, we describe a research method to empirically test the conceptual model and hypotheses. Next, we present and discuss the results of data analysis. In the final section, we provide research implications and suggest future research directions.

\section{Theoretical Background and Research Hypotheses}

This research is conceptually rooted in two theoretical models. First, the theory of planned behavior is used to predict a guest's participation in an Airbnb service. Second, the cultural dimensions theory will serve as a framework to identify dimensions of guests' cultural values as determinants of a guest's attitude toward using an accommodation sharing service. These two theories are presented below to show how they fit in the context of accommodation booking on Airbnb.

\subsection{Behavioral Intention in the Context of a Sharing Economy}

The theory of planned behavior is a follow-up model of the theory of reasoned action proposed to predict an individual's inclination to engage in a behavior [11]. In the theory of reasoned action, behavioral intent is determined by two components including attitude about the likelihood that the behavior will be performed and the subjective evaluation of the behavior [12]. The theory of planned behavior subsequently updated and presented by Ajzen [10] has a third antecedent to behavioral intent-perceived behavioral control. Ajzen [10] theorizes that perceived behavioral control involving a person's perception of his or her own ability to perform the behavior explains when an individual intends to enact the behavior given environmental circumstances [13].

Subsequently, there emerged related models that identified different factors influencing the behavioral intention. For example, Davis and Bagozzi et al. [14] proposed the technology acceptance model to predict behavioral intention, with perceived usefulness and perceived ease of use as antecedents of attitude. Afterwards, Venkatesh et al. [15] developed and tested an integrated model, the so-called unified theory of acceptance and use of 
technology (UTAUT) model that proposed performance expectancy, effort expectancy, and social influence as direct determinants of behavioral intention. However, this theory has been criticized for its overwhelmingly numerous variables to predict intentions, leading to a stage of chaos [16].

The very relationship between attitude and behavioral intention has been of central concern to researchers in related disciplines. Influential theories such as the theory of planned behavior and the technology acceptance model theorize that attitude is a key antecedent of behavioral intention. As Ajzen [13] notes, attitude toward a behavior refers to the extent to which an individual has a favorable or unfavorable evaluation of the behavior. It can be inferred that an individual's evaluation (i.e., good or bad) of a behavior is likely to determine his or her intention to engage in the behavior. This relationship between attitude and intention was also found in subsequent studies [17-19].

In the context of a sharing economy, behavioral intention would involve a user's intent to use an under-utilized resource (i.e., an accommodation) on Airbnb. A person's intention to stay in an accommodation owned and used by an unknown individual will likely be a direct outcome of his or her attitude toward using such a sharing service. That is, if the person feels awkward about sleeping in someone else's bed, but feels more at home when staying in a hotel room, then it is less likely that he or she will develop an intention to use the sharing service on the Airbnb platform.

Given the above theoretical grounds, we propose the following hypothesis.

Hypothesis 1 (H1). Attitude has a positive effect on behavioral intention.

In the field of social psychology, subjective norm refers to the belief regarding whether most people approve or disapprove of the behavior [13]. Simply put, subjective norms are concerned with a person's beliefs about whether peers and acquaintances think he or she should engage in the behavior [20]. Ajzen defines subjective norms as the "perceived social pressure to perform or not perform the behavior" [13]. This definition is conceptually related to social influence. Social influence is "the process by which an individual's attitudes, beliefs or behavior are modified by the presence or action of others" [21]. When there exists social influence, one's beliefs about performing a behavior or actual behavior will likely be affected in such a way as to be in harmony with the expectations of one's significant others.

Then why do people match their behavior with what others expect them to do? Morton Deutsch and Harold Gerard [22] described two psychological needs that lead humans to conform to the expectations of others. These include "our need to be right (informational social influence) and our need to be liked (normative social influence)" [22]. Informational influence is "an influence to accept information from another as evidence about reality". Informational influence takes effect when individuals are uncertain, either because stimuli are intrinsically ambiguous or because there is social disagreement. Normative influence is "an influence to conform to the positive expectations of others".

The original TRA and TPB models postulate that subjective norm is one of the antecedents to behavioral intention [23]. The beliefs that people develop as to what behaviors are acceptable would form one's perception of the behavior, and determine one's intention to perform or not perform the behavior [20].

The theoretical relationship between subjective norm and intention can be applied to the home sharing context. If one believes that staying in an accommodation shared by an unknown person is socially acceptable within one's referent group such as friends, family, or colleagues, one will more likely be willing to engage in the use of the sharing service on Airbnb. By the same token, if one's acquaintances perceive that sleeping in someone else's bed is ridiculous and unnatural, one will be less likely to use the home sharing service.

Therefore, we hypothesize a positive relationship between subjective norm and behavioral intention.

Hypothesis 2 (H2). Subjective norm has a positive effect on behavioral intention. 


\subsection{Dimensions of Cultural Values}

According to the theory of planned behavior, the attitude toward performing a behavior is determined by behavioral beliefs [10]. Sommestad [24] found that social beliefs like culture affect attitude. Hofstede [25] defined culture as "the collective programming of the mind, which distinguishes the members of one group or category of people from another". Culture has an influence on consumers' tendency to accept and use innovations and related services [2], and some innovations are not compatible with every culture. Further studies are needed to examine the importance of cultural variables in travel consumers perceptions and intentions [17]. Consequently, the focus of this study is on understanding how accommodation sharing services are used on Airbnb [26]. The attitude towards the services can be explained from a cultural perspective.

Although there exist a multitude of studies examining the drivers of the sharing economy participation, only a few approach from a cross-cultural perspective while others focus on a platform, a guest, or a host. It's crucial to examine the sharing economy from cultural perspectives because different cultures involve different cultural values, norms, and beliefs [25]. This study will help understand the role of the cultural value dimensions in the use of accommodations on home-sharing platforms. It is designed to delve into the relationships between cultural dimensions, attitude, subjective norm, and behavioral intention.

Hofstede [9] identified a total of six cultural dimensions, including uncertainty avoidance, individualism/collectivism, power distance, feminism/masculinism, longterm/short-term orientation, and indulgence/restraint. We chose to include uncertainty avoidance (UA), individualism (IND), masculinity (MAS), indulgence (IND), and longterm orientation (LTO). The reason why we chose only five of the dimensions excluding power distance is that those five dimensions are expected to be influential when it comes to adopting a sharing accommodation service. There was not enough evidence found from the past research that supports the effect of power distance on attitude of individuals. According to the results of a study by Valaei, Rezaei [27], power distance has no effect on the attitude towards online brands. Moreover, Gupta, Esmaeilzadeh [8] found that power distance has no influence on peer consumer's propensity to rent products. Additionally, since power distance mostly affects people in their work environment or in the situations where they pay attention to social classes, it is less relevant to a setting where a consumer develops attitudes towards using a home sharing service on Airbnb. Thus, the current study focuses on five cultural dimensions. Figure 1 presents our research model based on these five cultural dimensions. The model has been constructed based on both the cultural dimensions theory and the theory of planned behavior.

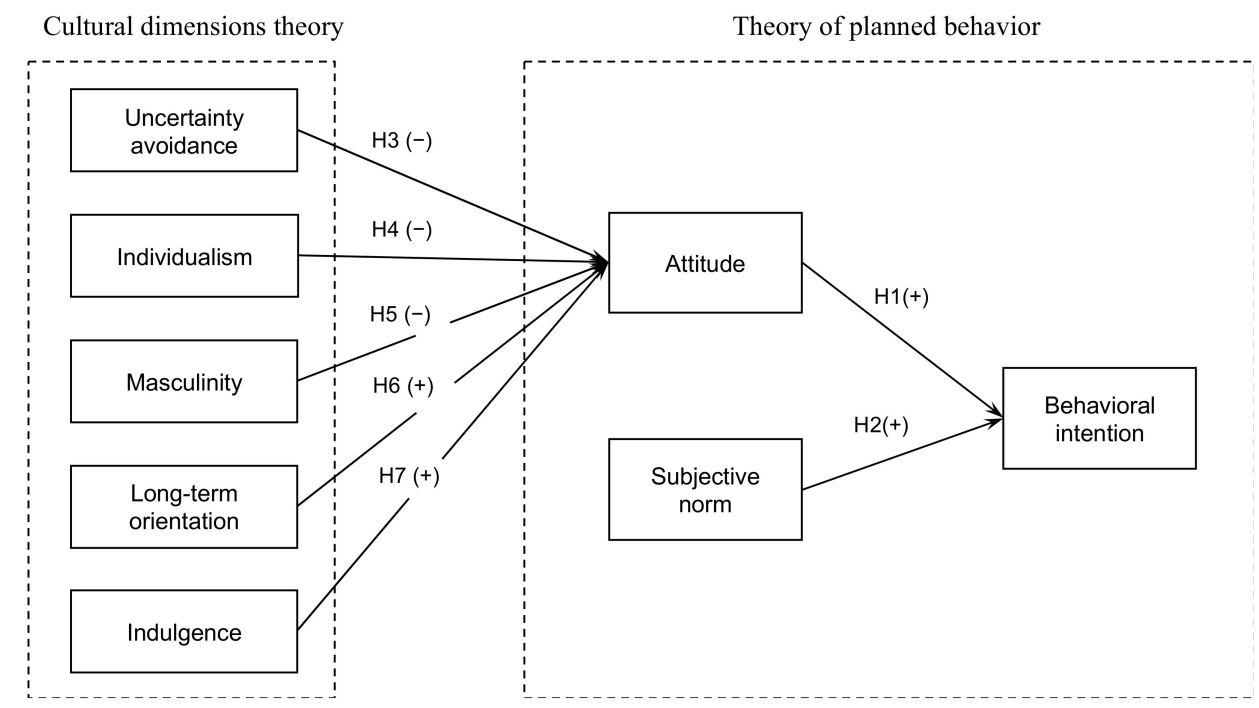

Figure 1. The conceptual model. 


\subsubsection{Uncertainty Avoidance}

The uncertainty avoidance refers to the extent to which members of a culture feel threatened by uncertain or ambiguous situations [28]. High uncertainty avoidance (HUA) refers to the resistance to change, avoidance of risk, and discomfort with the unknown. Those societies are risk-averse whereas low uncertainty avoidance societies are more likely to take risks. Low uncertainty avoidance (LUA) cultures have the attributes like "willingness to change, ease of adjusting to the unknown, risk-taking, tolerance for innovation and new ideas, and optimism about the future" [29]. Further, individuals with HUA do not like any changes, and they are opposed to innovations that would affect their lives [30]. On the contrary, individuals in LUA societies are more willing to take risks, allow ambiguous situations, and have a positive attitude towards novel ideas.

According to Hofstede [25], cultures with HUA are inclined to work towards order, law and great achievements. They cannot tolerate irregularity and have a strong preference for written rules and laws. On the other hand, individuals from LUA cultures do not have any preference for bureaucratic structures [31]. Since Airbnb offers a unique and non-standardized service unlike hotels, people with HUA are expected to have a negative attitude towards booking on Airbnb.

Moreover, people from LUA societies can trust strangers and foreigners even if they do not share common beliefs or attitudes [32], whereas individuals from HUA societies have a hard time developing trust especially when they need to interact with strangers and foreigners and spend more time reducing uncertainty. Individuals with HUA are hesitant to use online services for the fear of privacy $[33,34]$. They prefer to minimize risk before purchasing a product or a service, and need more privacy and security in order to raise confidence levels [33]. Since Airbnb encourages you to interact with strangers, it requires a high level of trust. People with low tolerance to the unknown would have a negative attitude and hence be less likely to try the accommodation sharing service on Airbnb.

Moreover, Hofstede's uncertainty avoidance score of United States was found to be 46, which is a relatively small number [35]. This implies that American people who are heavy users of Airbnb services do not feel very threatened by the unknown aspects associated with home sharing. In this case, having a low level of uncertainty avoidance and, accordingly, not feeling threatened by an unknown encounter would lead to a positive attitude towards Airbnb. It is vice versa for the high uncertainty avoidance situation.

Therefore, we hypothesize the following relationship between the two research constructs.

Hypothesis 3 (H3). Uncertainty avoidance has a negative effect on attitude.

\subsubsection{Individualism-Collectivism}

Collectivistic cultures share a solid faith that members of a community matter to one another and to the group and value warm relationships, and people in that culture do not care about being dependent on others to use products [28]. On the other hand, individualists tend to be materialistic, keen on pursuing materialistic needs and individual rewards $[8,28,36,37]$. Wong [38] argues that collectivistic cultures tend to be non-materialistic, and people in those cultures are less possessive and less attached to their belongings, while individualistic cultures are more materialistic and more possessive. Furthermore, according to Belk [39], materialists tend to share less and avoid being dependent on others when they use products. Participation in peer-to-peer sharing requires being less possessive and being open to sharing products, which are collectivistic traits.

Individualists engage in a relationship if they view it as a beneficial activity and terminate a relationship when the costs of participation exceed the benefits, whereas collectivists develop stronger perceptions of trust when interacting with people [40]. It implies that the positive effect of trust perception on intention to perform an online transaction is stronger for collectivists than for individualists [29,41].

Furthermore, privacy is significantly more important for individualists [42] who may perceive less privacy and greater risk towards the use of Airbnb services. On the other hand, 
cyber security has a positive impact on trust for collectivists [42], since Airbnb provides an online platform with a review system and a secure payment system. Hence, collectivists would place greater trust on Airbnb and regard using an Airbnb service as a less risky activity than individualists.

Psychologists have found that in individualistic cultures, emotions are more prominent in people's judgments because they provide direct feedback on fit between personal needs and goals $[43,44]$. In collectivistic cultures, although fulfillment of personal goals is still important, individuals place more emphasis on following the cultural norms. In that regard, it is expected that in individualistic societies emotional experience has more importance during the value creation process, whereas the utilitarian experience such as finding cheaper options to hotels is given more emphasis in collectivistic societies [45].

Moreover, Gupta, Esmaeilzadeh [8] found that collectivism has a positive influence on sharing economy service providers' as well as consumers' propensity of renting out and renting products. Even though Hofstede [28] argues that with the score of 91, United States is a highly individualistic society, Americans are expected to be less possessive and more open to sharing in the use of Airbnb services.

Based on the above line of reasoning, the following hypothesis is developed:

Hypothesis 4 (H4). Individualism has a negative effect on attitude.

\subsubsection{Masculinity-Femininity}

Masculinism indicates the extent to which individuals in a society value assertiveness, ambitiousness, performance orientation, and control [28]. In contrast, individuals from feminine societies value quality of living, nurturing, and caring [8]. Hofstede, Hofstede [25] found that the main difference between the opposite ends of the dimension is the extent to which individuals are driven by economic motivations. Since individuals in masculine societies tend to place more emphasis on increasing their earnings, they care more about the economic achievement, while individuals in feminine societies are driven by emotion [28]

While cultures with high level of masculinity can be seen as competitive societies where individuals are either winners or losers, feminist societies where people feel secure about sharing their knowledge and resources with others emphasize cooperation [46]. Sharing is about cooperation and mutuality which reflect values that can be seen as feminine [47]. Moreover, Jaggar [48] states that "interdependence, community, connection and sharing" are feminine attributes which can be inferred as core values of sharing economy as well.

According to a comparative study between Italian (masculine society) and Spanish (feminine society) individuals, Italian consumers were found to not favor the participation in the sharing economy and to have a negative attitude towards it [46]. In contrast, Spanish people who prefer to cooperate and give attention to other people's needs rather than competing with others were found to have a more positive attitude towards the sharing economy. In essence, Spanish people are entertaining, friendly, and warm and try to establish harmony in their relationships [49]. Moreover, they show a communal sharing pattern that includes giving presents, being generous, behaving altruistically, and perceiving relationships as being eternal [50], which are the values associated with femininity. Additionally, Valaei, Rezaei [27] also found a negative relationship between masculinity and attitude towards online brands. Thus, it will not be easy for consumers with masculine values to place trust in an online brand 'Airbnb' and incline towards their sharing service.

Therefore, we formulate the following hypothesis:

Hypothesis 5 (H5). Masculinity has a negative effect on attitude. 


\subsubsection{Long-Term Orientation}

Long-term orientation (LTO) refers to "the prioritization of future rewards over shortterm benefits" - in particular, perseverance and thrift [51]. Additionally, individuals from LTO cultures place high importance on relationship building [51]. Those cultures value relationships, act in a way to decrease the conflict and care about future rewards rather than instant benefits, whereas cultures low in this dimension focus on immediate benefits and costs, and are more likely to have a "time is money" attitude [3,51].

Unfortunately, some studies which examined the effects of cultural dimensions on sharing economy services have not included long-term orientation as a dimension, although they suggested its inclusion for further research [8,52]. Individuals in high LTO cultures care more about future than immediate costs. They prefer value saving and sustainable consumption that lessens environmental impact which is one of the core values of the sharing economy $[3,53]$.

According to Ryu and Moon [54], high LTO cultures foster the generation of mutual trust. They revealed that members of high LTO societies tend to anticipate long-term benefits, instead of seeking self-interest, and ultimately build up inter-member trust. In contrast, low LTO cultures do not cultivate trust between their members. Since trust is one of the main requirements for an interaction with a stranger especially in the sharing economy context, it can be inferred that high LTO is an indication of positive attitude towards Airbnb. Furthermore, Wallace [3] argued that individuals from high LTO cultures may trust sharing services more when the sustainable consumption is evident.

Thus, the following hypothesis is presented:

Hypothesis 6 (H6). Long-term orientation has a positive effect on attitude.

\subsubsection{Indulgence-Restraint}

The indulgence-restraint dimension denotes the extent to which people attempt to control their desires and impulses. According to Hofstede, Hofstede [25], low levels of indulgence indicate restraint that implies suppression of desires through strict societal norms. On the opposing end, indulgence reflects a tendency for relatively free gratification of basic and natural desires in association with fun and enjoyment. People with high levels of restraint let themselves have limited wants and desires and try to keep themselves disinterested in the opposite behavior [55].

Moreover, high levels of restraint lead to a feeling of pessimism and negativism as well as the lack of trust [25]. Because of their negative attitude and minimal trust, people who value restraint may not be willing to try out new services or products. On the other hand, people with high indulgence are likely to adopt positive feelings and optimism, and develop trust more easily than restraint-oriented people.

Additionally, people from restraint-oriented cultures are more likely to concentrate on the negative aspects and are more likely to pay attention to negative cues [3]. For that reason, they would have a negative attitude towards sharing services since accommodation-sharing platforms like Airbnb offer non-standardized services that make one more vulnerable to unpredictable issues. On the other hand, since each home and host offer a unique and one-of-a-kind experience to guests, people who are indulgence-oriented may have positive attitudes towards such services. Indulgence-oriented people are generally fun-oriented and interested in entertainment while restraint-oriented people are associated with lower spending tendency and lower engagement in leisure and fun activities [25]. The unique experience that sharing services offer would likely lead indulgence-oriented people to be more interested in, and have a more positive attitude toward, the novel idea of sharing an accommodation owned by an unknown person.

Based on the above theoretical grounds, we propose the following hypothesis.

Hypothesis 7 (H7). Indulgence has a positive effect on attitude. 


\section{Methodology}

\subsection{Data Collection and Sample}

To test proposed hypotheses, a total of 415 U.S citizens were recruited via Amazon Mechanical Turk by providing monetary compensation. A short definition of Airbnb services was provided, and they were asked if they have ever heard about Airbnb. Those who had at least some information about Airbnb were included for sample. If they did not know about Airbnb, their response was not taken into consideration. At the pilot test stage, 30 people answered the survey. Their results were examined to see if there were any issues with the survey questions. After the pilot test, the main survey was conducted between 22 March and 27 March 2021. After excluding 14 incomplete responses, a total of 401 responses were used for data analysis. Among the participants, $64.8 \%$ were male $(n=260)$. The largest age group participated was $30 \mathrm{~s}(45.6 \%)$ followed by the 20 s with the rate of $26.2 \%$. Participants who had completed a bachelor's degree was the largest with the rate of $56.4 \%$. Lastly, participants who had a yearly income of USD 75,000-99,999 had the biggest portion in terms of income level. Table 1 shows a demographic profile of the respondents.

Table 1. Respondents' demographic profiles $(n=401)$.

\begin{tabular}{|c|c|c|c|}
\hline Characteristics & Value & Frequency & Percentage \\
\hline \multirow[t]{2}{*}{ Gender } & Female & 141 & 35.2 \\
\hline & Male & 260 & 64.8 \\
\hline \multirow[t]{6}{*}{ Age } & $10 \mathrm{~s}$ & 1 & 0.2 \\
\hline & $20 \mathrm{~s}$ & 105 & 26.2 \\
\hline & $30 \mathrm{~s}$ & 183 & 45.6 \\
\hline & $40 \mathrm{~s}$ & 68 & 17.0 \\
\hline & $50 \mathrm{~s}$ & 34 & 8.5 \\
\hline & $60 \mathrm{~s}$ & 10 & 2.5 \\
\hline \multirow[t]{5}{*}{ Education } & Less than high school degree & 0 & 0.0 \\
\hline & High school degree or equivalent & 47 & 11.7 \\
\hline & Associate degree & 29 & 7.2 \\
\hline & Bachelor's degree & 226 & 564. \\
\hline & Graduate degree & 99 & 24.7 \\
\hline \multirow[t]{8}{*}{ Income (yearly) } & No income & 5 & 1.2 \\
\hline & 1-9999 USD & 8 & 2.0 \\
\hline & 10.000-24,999 USD & 35 & 8.7 \\
\hline & 25.000-49,999 USD & 104 & 25.9 \\
\hline & 50.000-74,999 USD & 98 & 24.4 \\
\hline & $75.000-99,999$ USD & 108 & 26.9 \\
\hline & 100.000-149,999 USD & 34 & 8.5 \\
\hline & Greater than 150,000 USD & 9 & 2.2 \\
\hline $\mathrm{N}$ total & & 401 & \\
\hline
\end{tabular}

\subsection{Measures}

Table 2 lists eight constructs that have been devised to test the research hypotheses. Measurement items were either adopted or adapted from the related studies. Then the survey questions were designed based on these measurement items as well as questions related to the demographics of respondents. All the statements were assessed adopting a seven-point Likert scale which ranged from strongly disagree (1) to strongly agree (7).

Harman's single-factor test [56] was conducted to check common method bias because the data for this study were collected via a self-reporting questionnaires. Harman's singlefactor test showed common method bias was not an issue because the first factor explained $33.81 \%$ of total variance which is below the $50 \%$ threshold. 
Table 2. Measures and scales.

\begin{tabular}{|c|c|c|c|}
\hline Constructs & Definition & Measurement Items & Sources \\
\hline Uncertainty avoidance & $\begin{array}{l}\text { The extent to which } \\
\text { members of a culture feel } \\
\text { threatened by uncertain or } \\
\text { ambiguous situations. }\end{array}$ & $\begin{array}{l}\text { 1. Rules and regulations are important because } \\
\text { they inform workers what the organization } \\
\text { expects of them. } \\
\text { 2. Order and structure is very important in a work } \\
\text { environment. } \\
\text { 3. It is better to have a bad situation that you know } \\
\text { all about, than having an uncertain situation } \\
\text { which might be better. } \\
\text { 4. Standardized work procedures are helpful. } \\
\text { 5. Instructions for operations are important. }\end{array}$ & {$[3,8,28]$} \\
\hline Individualism & $\begin{array}{l}\text { The degree of } \\
\text { interdependence a society } \\
\text { maintains among its } \\
\text { members. }\end{array}$ & $\begin{array}{l}\text { 1. Having autonomy and independence is more } \\
\text { important than being accepted as a member of a } \\
\text { group. } \\
\text { 2. Being independent is more important than being } \\
\text { accepted as a member of a group. } \\
\text { 3. Individual gain is more important than being } \\
\text { loyal to a group. } \\
\text { 4. Group welfare is not as important as individual } \\
\text { 5. Individual success is more important than group } \\
\text { rewards. } \\
\text { 6. It is more important for a manager to encourage } \\
\text { individual initiative than it is to encourage } \\
\text { loyalty and a sense of duty in subordinates. }\end{array}$ & {$[8,28]$} \\
\hline Masculinity & $\begin{array}{l}\text { Masculinity dimension } \\
\text { indicates that the society } \\
\text { will be driven by } \\
\text { competition, achievement, } \\
\text { and success. }\end{array}$ & $\begin{array}{l}\text { 1. It is preferable to have a man in high-level } \\
\text { position rather than a woman. } \\
\text { 2. There are some jobs which men can always do } \\
\text { better than women. } \\
\text { 3. It is more important for men to have a } \\
\text { professional career than it is for women to have } \\
\text { a professional career. } \\
\text { 4. Solving organizational problems requires an } \\
\text { active forcible approach which is typical of men. }\end{array}$ & {$[8,28]$} \\
\hline Long-term orientation & $\begin{array}{l}\text { The prioritization of } \\
\text { future rewards over } \\
\text { short-term benefits, in } \\
\text { particular, perseverance and } \\
\text { thrift }\end{array}$ & $\begin{array}{l}\text { 1. I should be careful when I manage my money. } \\
\text { 2. I care about my personal steadiness and stability. } \\
\text { 3. Individuals should engage in long-term } \\
\text { planning. } \\
\text { 4. Individuals should give up today's fun for } \\
\text { success in the future. } \\
\text { 5. Individuals should work hard for success in the } \\
\text { future. }\end{array}$ & {$[3,51,57,58]$} \\
\hline Indulgence & $\begin{array}{l}\text { The degree to which people } \\
\text { attempt to control their } \\
\text { desires and impulses. }\end{array}$ & $\begin{array}{l}\text { 1. I always buy something to feel better. } \\
\text { 2. "Buy now, think about it later" describes me. } \\
\text { 3. People would describe me as impulsive because } \\
\text { I lose control due to my desires. } \\
\text { 4. When I go shopping, I buy things that I had not } \\
\text { intended to purchase. } \\
\text { 5. If I see something I want, I buy it. Later, I regret } \\
\text { it. } \\
\text { 6. When there are discounts/sales for product } \\
\text { offers, I tend to make purchases. }\end{array}$ & {$[3,51]$} \\
\hline
\end{tabular}


Table 2. Cont

\begin{tabular}{|c|c|c|c|}
\hline Constructs & Definition & Measurement Items & Sources \\
\hline Attitude & $\begin{array}{l}\text { Evaluative statement about } \\
\text { an object. }\end{array}$ & $\begin{array}{l}\text { 1. Using Airbnb is a good idea. } \\
\text { 2. Using Airbnb is a wise idea. } \\
\text { 3. Using Airbnb is an idea that I like. } \\
\text { 4. Using Airbnb to find an accommodation would } \\
\text { be pleasant. }\end{array}$ & {$[18,59]$} \\
\hline Subjective norm & $\begin{array}{l}\text { The belief that an important } \\
\text { person or group of people } \\
\text { will approve and support a } \\
\text { particular behavior. }\end{array}$ & $\begin{array}{l}\text { 1. People who influence my behavior would think } \\
\text { that I should use Airbnb to find an } \\
\text { accommodation. } \\
\text { 2. People who are important to me would think } \\
\text { that I should use Airbnb to find an } \\
\text { accommodation. }\end{array}$ & [18] \\
\hline $\begin{array}{l}\text { Behavioral } \\
\text { intention }\end{array}$ & $\begin{array}{l}\text { The amount of effort exerted } \\
\text { to engage in a behavior, } \\
\text { amount of resources } \\
\text { devoted to a behavior, and } \\
\text { the perception of how hard } \\
\text { one is willing to work to } \\
\text { engage in the behavior. }\end{array}$ & $\begin{array}{l}\text { 1. I am very likely to use Airbnb in the future. } \\
\text { 2. I would recommend that others use Airbnb. }\end{array}$ & {$[13,52,60]$} \\
\hline
\end{tabular}

\section{Results}

\subsection{Reliability and Validity Analysis}

Statistical analysis on the data were conducted through SPSS 26.0 and AMOS 26.0 for Windows. The SPSS package was used to analyze the reliability of the constructs and the demographics of the respondents. AMOS 26 was used to perform the confirmatory factor analysis (CFA), path analysis, and to test the research hypotheses. First, the goodness of fit of the measurement model was assessed using number of indicators and the results revealed that the measurement model adequately fit the data $\left(\chi^{2} / \mathrm{df}=2.807\right.$, comparative fit index $(\mathrm{CFI})=0.920$, Tucker-Lewis index $(\mathrm{TLI})=0.908$, root mean square error of approximation $($ RMSEA $)=0.066$, standardized root mean square residual $($ SRMR $)=0.0607)$. Thus, it can be inferred that the measurement model was reasonably fitted to the data set [61].

Reliability relates to how reliably and consistently the measurement tool measured what it wanted to measure without error. Reliability coefficient called Cronbach's alphas was measured to test if there is any internal consistency issue. As shown in Table 3, the Cronbach's alphas of the constructs varied between 0.783 and 0.938 , which all exceeded the 0.70 threshold suggested by Nunnally [62]. Hence, the measures are considered reliable with no internal consistency issue. Next, construct validity, which is the degree of correspondence between a construct and its operationalization, was measured. Under construct validity, convergent validity, discriminant validity, and nomological validity were tested [63]. Convergence validity refers to determining validity based on the degree of correlation between each concept measured by different measuring tools that measure the same concepts. It can be satisfied when standardized factor loadings are 0.5 or above, and averaged variances expected (AVE's) are 0.5 or above $[64,65]$. As can be seen in Table 3 , the factor loadings of each measured variable showed that all were significant $(p<0.001)$ and exceeded the ' 0.5 ' threshold [64]. Additionally, in Table 3, it can be seen that all AVE values which are ranging from 0.506 to 0.775 were higher than the threshold of 0.5 [64]. Thus, convergent validity for the measurement model is acceptable. Conversely, discriminant validity shows that two measures that are not supposed to be related are, in fact, unrelated. Discriminant validity was assessed through an AVE analysis as shown in Table 4. It shows that discriminant validity is verified considering the square root of AVE for each construct was larger than all inter-construct correlations.

Furthermore, nomological validity determines the degree to which measured constructs demonstrates the relationships based on theory or prior research. Nomological validity was also checked by calculating the correlation coefficients as in Table 4 . The 
coefficient between attitude and intention appeared to be rather high (0.738), thus a multicollinearity test on SPSS was conducted. If variance inflation factors (VIF) calculated are 3 or less, then there is no threat of multicollinearity. It was found that VIF were between 1.862 and 2.759 , meaning that nomological validity is satisfied because multicollinearity is not an issue in this study.

Table 3. Statistics of construct items.

\begin{tabular}{|c|c|c|c|c|c|}
\hline & Standardized Factor Loadings & Cronbach's Alpha & Composite Reliability & AVE & Mean (SD) \\
\hline UA1 & 0.849 & \multirow{4}{*}{0.837} & \multirow{4}{*}{0.843} & \multirow{4}{*}{0.575} & \multirow{4}{*}{$6.040(0.839)$} \\
\hline UA2 & 0.692 & & & & \\
\hline UA4 & 0.703 & & & & \\
\hline UA5 & 0.779 & & & & \\
\hline IND1 & 0.656 & \multirow{6}{*}{0.880} & \multirow{6}{*}{0.876} & \multirow{6}{*}{0.544} & \multirow{6}{*}{$4.929(1.226)$} \\
\hline IND2 & 0.596 & & & & \\
\hline IND3 & 0.828 & & & & \\
\hline IND4 & 0.757 & & & & \\
\hline IND5 & 0.854 & & & & \\
\hline IND6 & 0.699 & & & & \\
\hline MAS1 & 0.936 & \multirow{4}{*}{0.930} & \multirow{4}{*}{0.932} & \multirow{4}{*}{0.775} & \multirow{4}{*}{$4.262(1.942)$} \\
\hline MAS2 & 0.717 & & & & \\
\hline MAS3 & 0.927 & & & & \\
\hline MAS4 & 0.923 & & & & \\
\hline LTO1 & 0.728 & \multirow{4}{*}{0.803} & \multirow{4}{*}{0.804} & \multirow{4}{*}{0.506} & \multirow{4}{*}{$6.033(0.837)$} \\
\hline LTO2 & 0.684 & & & & \\
\hline LTO3 & 0.719 & & & & \\
\hline LTO5 & 0.714 & & & & \\
\hline IDG1 & 0.84 & \multirow{6}{*}{0.938} & \multirow{6}{*}{0.938} & \multirow{6}{*}{0.717} & \multirow{6}{*}{$4.142(1.787)$} \\
\hline IDG2 & 0.911 & & & & \\
\hline IDG3 & 0.9 & & & & \\
\hline IDG4 & 0.829 & & & & \\
\hline IDG5 & 0.914 & & & & \\
\hline IDG6 & 0.659 & & & & \\
\hline ATT1 & 0.784 & \multirow{3}{*}{0.809} & \multirow{3}{*}{0.810} & \multirow{3}{*}{0.587} & \multirow{3}{*}{$5.899(0.896)$} \\
\hline ATT2 & 0.77 & & & & \\
\hline ATT4 & 0.743 & & & & \\
\hline SN1 & 0.85 & \multirow{2}{*}{0.849} & \multirow{2}{*}{0.849} & \multirow{2}{*}{0.738} & \multirow{2}{*}{$5.385(1.208)$} \\
\hline SN2 & 0.868 & & & & \\
\hline INT1 & 0.782 & \multirow{2}{*}{0.783} & \multirow{2}{*}{0.785} & $0<\mathrm{r}$ & 5006 (1 000$)$ \\
\hline INT2 & 0.825 & & & 0.646 & $5.986(1.000)$ \\
\hline
\end{tabular}

Notes. UA = uncertainty avoidance; IND = individualism; MAS = masculinity; LTO = long-term orientation; IDG = indulgence; $\mathrm{ATT}=$ attitude $\mathrm{SN}=$ subjective norm $; \mathrm{INT}=$ behavioral intention. 
Table 4. Correlations between constructs (square root of AVE and correlations).

\begin{tabular}{ccccccccc}
\hline & UA & IND & MAS & LTO & IDG & ATT & SN & INT \\
\hline UA & $\mathbf{0 . 7 5 8}$ & & & & & & & \\
\hline IND & 0.034 & $\mathbf{0 . 7 3 7}$ & & & & & & \\
\hline MAS & -0.057 & 0.609 & $\mathbf{0 . 8 8 1}$ & & & & & \\
\hline LTO & 0.731 & 0.014 & -0.13 & $\mathbf{0 . 7 1 1}$ & & & & \\
\hline IDG & -0.099 & 0.623 & 0.717 & -0.173 & $\mathbf{0 . 8 4 7}$ & & & \\
\hline ATT & 0.536 & 0.067 & 0.047 & 0.519 & 0.092 & $\mathbf{0 . 7 6 6}$ & & \\
\hline SN & 0.316 & 0.294 & 0.343 & 0.283 & 0.441 & 0.543 & $\mathbf{0 . 8 5 9}$ & \\
\hline INT & 0.529 & 0.041 & 0.009 & 0.488 & 0.044 & 0.738 & 0.476 & $\mathbf{0 . 8 0 4}$ \\
\hline
\end{tabular}

Notes. The bold numbers in the diagonal row are square roots of average variance extracted (AVE) $\mathrm{UA}=$ uncertainty avoidance; IND = individualism; MAS = masculinity; LTO = long-term orientation; IDG $=$ indulgence; $\mathrm{ATT}=$ attitude; $\mathrm{SN}$ = subjective norm; $\mathrm{INT}=$ behavioral intention .

\subsection{Structural Paths and Hypothesis Tests}

The goal of this study is to find the effects of cultural dimensions of uncertainty avoidance, individualism, masculinity, indulgence, and long-term orientation on attitude, as well as the total effect of attitude and social norms on behavioral intention. With this purpose, we conducted a path analysis for the relationships using the structural equation modeling (SEM) technique. The hypothesized structural model adequately fit the data $\left(\chi^{2}=1197.115(\mathrm{df}=437, p=0.000) ; \mathrm{CFI}=0.920 ; \mathrm{TLI}=0.909 ; \mathrm{RMSEA}=0.066 ; \mathrm{SRMR}=0.060\right)$ and satisfied the criteria (Hair, 2010). According to the result of path analysis, out of seven hypotheses, five hypotheses were accepted while two were rejected. The results revealed that attitude towards using Airbnb was negatively influenced by uncertainty avoidance $(\beta=-2.904, p<0.05)$ and individualism $(\beta=-0.638, p<0.05)$. Therefore, H3 and H4 were supported. Long-term orientation $(\beta=3.832, p<0.05)$ and indulgence $(\beta=0.958$, $p<0.01$ ) had a significant positive effect on attitude toward using Airbnb, providing support for both H6 and H7. Meanwhile, masculinity $(\beta=0.256, p>0.05)$ was not significantly associated with the attitude. Thus, $\mathrm{H} 5$ was not supported. Moreover, attitude toward Airbnb $(\beta=0.948, p<0.001)$ was found to have a significant positive effect on the behavioral intention, while subjective norm $(\beta=0.018, p>0.05)$ had no significant effect on the behavioral intention. Thus, $\mathrm{H} 1$ was supported while $\mathrm{H} 2$ was not. Figure 2 displays the standardized path coefficient, path significance, and explained variance $\left(R^{2}\right)$ for each path

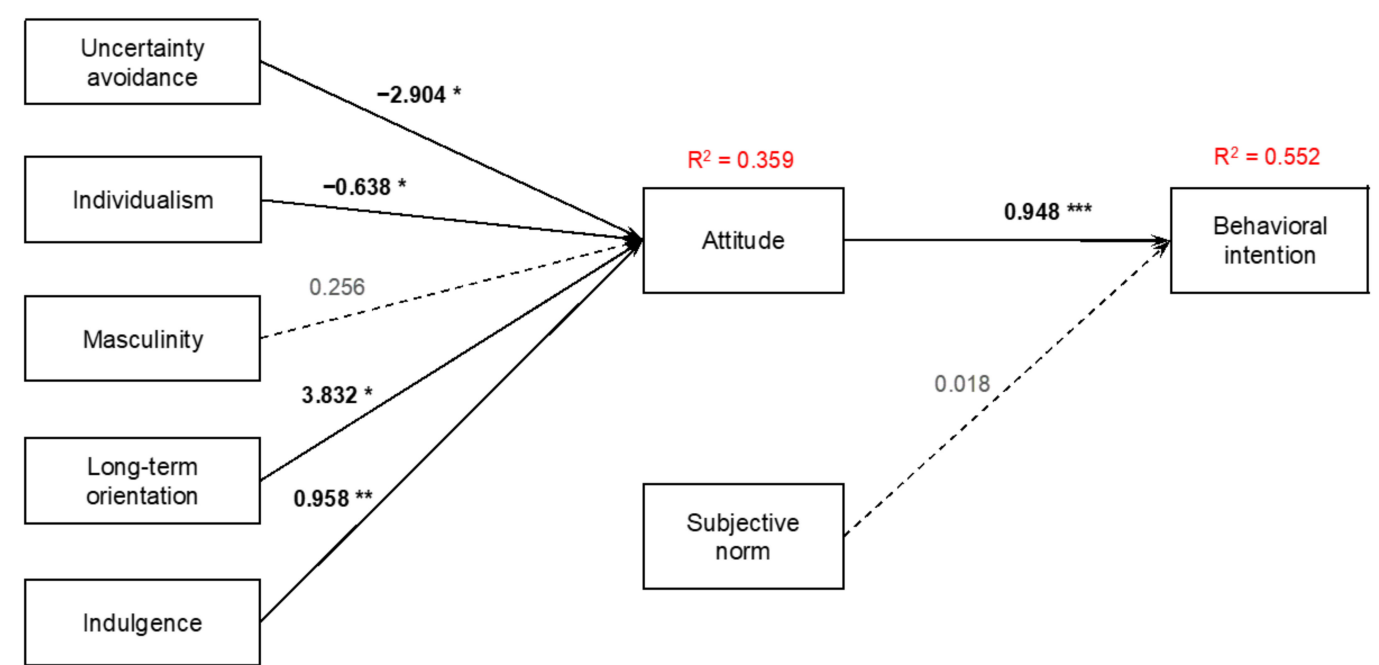

Figure 2. Hypothesis testing. Notes. $X^{2}=1197.115(p=0.000, \mathrm{df}=437)$; root mean square error of approximation $=0.066$; comparative fit index $=0.920$; Tucker-Lewis index $=0.909$; standardized root mean square residual $=0.060 .{ }^{*} p<0.05 ;{ }^{* *} p<0.01 ;{ }^{* * *} p<0.001$. 


\section{Conclusions}

\subsection{Key Findings and Research Contribution}

A majority of related prior studies investigating cultural influences on the sharing economy services used a subset of cultural values. Thus, their findings failed to provide a comprehensive understanding of how culture affects the participation in the sharing economy. Moreover, there has been little emphasis on the role of social influence in the use of a sharing service. The present study aimed to fill this gap. The purpose of this research is to investigate the influence of cultural and social factors on a consumer's participation in a sharing economy using Hofstede's cultural dimensions theory and Ajzen's theory of planned behavior. Specifically, this study examined the impact of five national cultural values on attitude and it also examined whether subjective norms and attitude have a positive influence on a user's intention to use services for sharing an accommodation on Airbnb.

The results of our empirical analysis revealed that cultural dimensions are key predictors of attitude toward Airbnb. All the cultural dimensions except for masculinity were found to have a significant relationship with attitude toward booking on Airbnb. The finding that culture plays an important role in a user's participation in a sharing economy is in harmony with those of prior studies [3,8]. Moreover, the significant influence of attitude on intention was confirmed while the influence of subjective norms on intention was not supported. It is interesting to note that social influence does not contribute to the formation of one's intent to participate in the sharing economy. It is inferred that one decides whether to book an accommodation on Airbnb based on perceptions of one's own needs rather than those of whether one's acquaintances expect one to use such a sharing service.

The first research question presented in the Introduction inquires into the potential influence of culture on attitude. The findings bring up diverse effects of cultural values. Consistent with the hypotheses, uncertainty avoidance and individualism had a negative effect on attitude. The significant effect of uncertainty avoidance on attitude is in line with the findings of previous studies [32,33], which found that individuals with HUA are reluctant to adopt online services for the fear of privacy. Moreover, the significant effect of individualism on attitude is in accord with the results of a prior study that concluded that collectivism has a positive effect on consumers' propensity of renting out and renting products [8].

Likewise, long-term orientation and indulgence also proved to be positively associated with the attitude towards Airbnb, as we predicted in the related hypotheses. The significant positive effect of LTO may be attributed to the fact that high LTO culture positively affects the generation of trust [54] and trust is an important requirement for using sharing services. Furthermore, the positive relationship between indulgence and attitude agrees with the finding of a related study that people from restraint-oriented cultures tend to focus on the negative aspects [3], thereby leaning toward a negative attitude about sharing services.

On the other hand, masculinity turned out to be the only cultural dimension that had no significant influence on attitude. This finding implies that masculinity domain, such as whether a society is governed by competition, achievement, and success, has little correlation with attitudes toward sharing economy services. Further research is needed to investigate the potential impact of masculinity on the consumer behavior in the sharing economy.

Now, our second research question is concerned with whether social influence contributes to the formation of a user's intent to use sharing services. Contrary to our prediction, it was found that social influence has no significant effect on intention to book an accommodation on Airbnb. This suggests that attitudes towards sharing economy participation driven by the cultural values are more influential than social influence in explaining an individual's sharing economy participation. We tried to augment an understanding of drivers of sharing economy participation research. To that end, we examined the influence of both the cultural value dimensions and social norms at the same time. Moreover, this study consists of the data gathered online from the United States citizens. Since Airbnb 
has made the biggest economic contribution of $\$ 33.8$ billion in the United States as well as the highest usage rate in the country, our respondents were familiar with Airbnb, and the majority of them had the experience of using the platform to book an accommodation several times.

\subsection{Implications}

The results of this study point to some implications for academics. First, our research contributed to the existing body of knowledge by providing an understanding of how culture and social influence each affects an individual's participation in the sharing economy. The results will provide new insights into the drivers of a user's participation by examining the impact of factors that go beyond immediate motivators such as cost savings, social networking, and so forth. Furthermore, this research helped to discover the theoretical relationships between cultural value dimensions and attitude toward the use of sharing services. Further studies in this direction will bear fruit with regards to the effects of culture on consumer behavior in the era of the sharing economy.

In addition, our findings provide some practical implications. A balance between peer providers and peer consumers needs to be maintained in P2P exchanges. According to Kumar, Lahiri [66], not being able to match the level of supply with the demand will lead to problems. For example, Stayzilla, once known as the Airbnb of India, had to shut down because of similar mismatch of supply and demand. The mismatch may occur when people are not willing to rent out their homes, or not willing to be renters of the houses. Cultural dimensions in this study explains the directions of people's willingness and unwillingness of Airbnb usage. For that reason, sharing accommodation service providers as well as other P2P exchange providers should modify their marketing strategy according to the country and its values. They need to create the right marketing mix to target individuals from different countries and cultures $[57,67]$.

While targeting countries or areas with a high level of collectivism, the emphasis should be on offering a P2P exchange as a digital platform that brings individuals together in a community and emphasizing the feeling of being at home. Moreover, for the countries with high uncertainty avoidance, the focus should be on lowering the uncertainty that comes with the usage of an online service as well as the uncertainties related with communicating with strangers. Since people from long-term oriented countries prefer value saving and sustainable consumption that lessens environmental impact, marketers should emphasize sustainable consumption characteristic of sharing economy services. Additionally, as restraint-oriented people have a lower tendency to engage in leisure and fun activities as well as a lower spending tendency, the practical aspect of sharing economies, which includes money saving and meeting simple accommodation needs, should be emphasized. Furthermore, since it is hard for restraint-oriented people to develop positive feelings and have a negative attitude instead, it is important to successfully display the positive features of sharing economy services.

\subsection{Limitations and Future Research}

This study bears limitations, which also open up significant opportunities for future research. First, while extant research indicates that the extent of government regulations in a nation tends to be significantly influenced by its cultural values [8], government regulations of the Unites States were not controlled in this study. Secondly, this study only used participants from Unites States. Although it was a good contributor to the data quality, it also poses a limitation. To overcome this limitation, one may include a sample of respondents from different cultures and make a comparative analysis of the results. Third, participants with past experience with Airbnb services were not questioned in detail. A favorable experience may generate a positive impact on the adoption intention, while an unfavorable experience may yield a negative impact on the future usage intentions.

Fourth, since the survey was conducted during the COVID-19 period, the responses might have been affected by the current situation. It may temporarily or permanently 
change the levels of the cultural dimensions that were measured and the level of societal influence. Future research may undertake an investigation into the effects of COVID-19 on the level of cultural dimensions as well as on subjective norms of individuals. Finally, this study focused on the five cultural dimensions by Hofstede and did not take into account the role of the power distance dimension. Focusing on the five of the cultural dimensions allowed us to reduce the questionnaire length and minimize participant fatigue significantly. However, future research may yield more insightful results by including all the cultural value dimensions in the empirical analysis.

Author Contributions: Conceptualization, J.L., A.N.E. and I.B.H.; methodology, J.L. and A.N.E.; analysis, J.L. and A.N.E.; writing-original draft preparation, A.N.E.; writing-review and editing, J.L. and I.B.H. All authors have read and agreed to the published version of the manuscript.

Funding: This research was supported by the Ministry of Education of the Republic of Korea and the National Research Foundation of Korea (NRF-2018S1A5A2A03039010). The APC was funded by National Research Foundation of Korea.

Institutional Review Board Statement: Ethical review and approval were waived for this study, due to the minimal risk involved.

Informed Consent Statement: Informed consent was obtained from all subjects involved in the study.

Data Availability Statement: The authors confirm that datasets used in this study will be available upon reasonable request.

Conflicts of Interest: The authors declare no conflict of interest.

\section{References}

1. Tabcum, S. The Sharing Economy Is Still Growing, and Businesses Should Take Note. Forbes. 2019. Available online: https:/ / www.forbes.com/sites/forbeslacouncil/2019/03/04/the-sharing-economy-is-still-growing-and-businesses-shouldtake-note/?sh=389832c74c33 (accessed on 19 October 2020).

2. Steenkamp, J.-B.E.; ter Hofstede, F.; Wedel, M. A cross-national investigation into the individual and national cultural antecedents of consumer innovativeness. J. Mark. 1999, 63, 55-69. [CrossRef]

3. Wallace, L.K. The Cultural Influence on Sharing Economy Services: The Case of Airbnb. Honors Theses, The University of Southern Mississippi, Hattiesburg, MS, USA, May 2020. Available online: https://aquila.usm.edu/honors_theses/737/ (accessed on 4 September 2020).

4. Davidson, A.; Habibi, M.R.; Laroche, M. Materialism and the sharing economy: A cross-cultural study of American and Indian consumers. J. Bus. Res. 2018, 82, 364-372. [CrossRef]

5. Barnes, S.J.; Mattsson, J. Understanding current and future issues in collaborative consumption: A four-stage Delphi study. Technol. Forecast. Soc. Chang. 2016, 104, 200-211. [CrossRef]

6. Benoit, S.; Baker, T.L.; Bolton, R.; Gruber, T.; Kandampully, J. A triadic framework for collaborative consumption (CC): Motives, activities and resources \& capabilities of actors. J. Bus. Res. 2017, 79, 219-227. [CrossRef]

7. Habibi, M.R.; Kim, A.; Laroche, M. From Sharing to Exchange: An Extended Framework of Dual Modes of Collaborative Nonownership Consumption. J. Assoc. Consum. Res. 2016, 1, 277-294. [CrossRef]

8. Gupta, M.; Esmaeilzadeh, P.; Uz, I.; Tennant, V.M. The effects of national cultural values on individuals' intention to participate in peer-to-peer sharing economy. J. Bus. Res. 2019, 97, 20-29. [CrossRef]

9. Hofstede, G. Dimensionalizing Cultures: The Hofstede Model in Context. Online Read. Psychol. Cult. 2011, 2, 1-26. [CrossRef]

10. Ajzen, I. Perceived Behavioral Control, Self-Efficacy, Locus of Control, and the Theory of Planned Behavior1. J. Appl. Soc. Psychol. 2002, 32, 665-683. [CrossRef]

11. Ajzen, I.; Fishbein, M. Understanding Attitudes and Predicting Social Behavior; Prentice Hall: Englewood Cliffs, NJ, USA, 1980.

12. Montaño, D.E.; Kasprzyk, D. Theory of reasoned action, theory of planned behavior, and the integrated behavioral model. In Health Behavior: Theory, Research and Practice; Wiley: Hoboken, NJ, USA, 2015.

13. Ajzen, I. The theory of planned behavior. Organ. Behav. Hum. Decis. Process. 1991, 50, 179-211. [CrossRef]

14. Davis, F.D.; Bagozzi, R.P.; Warshaw, P.R. User acceptance of computer technology: A comparison of two theoretical models. Manag. Sci. 1989, 35, 982-1003. [CrossRef]

15. Venkatesh, V.; Morris, M.G.; Davis, G.B.; Davis, F.D. User acceptance of information technology: Toward a unified view. MIS Q. 2003, 27, 425-478. [CrossRef]

16. Bagozzi, R.P. The Legacy of the Technology Acceptance Model and a Proposal for a Paradigm Shift. J. Assoc. Inf. Syst. 2007, 8, 244-254. [CrossRef]

17. Ayeh, J.; Au, N.; Law, C.H.R. Predicting the intention to use consumer-generated media for travel planning. Tour. Manag. 2013, 35, 132-143. [CrossRef] 
18. George, J. The theory of planned behavior and Internet purchasing. Internet Res. 2004, 14, 198-212. [CrossRef]

19. Merikivi, J.; Mantymaki, M. Explaining the Continuous Use of Social Virtual Worlds: An Applied Theory of Planned Behavior Approach. In Proceedings of the 2009 42nd Hawaii International Conference on System Sciences, Washington, DC, USA, 5-8 January 2009.

20. Ajzen, I.; Albarracin, D. Predicting and changing behavior: A reasoned action approach. In Prediction and Change of Health Behavior: Applying the Reasoned Action Approach; Ajzen, I., Albarracin, D., Hornik, R., Eds.; Lawrence Erlbaum Associates Publishers: Mahwah, NJ, USA, 2007; pp. 3-21.

21. Aronson, E.; Wilson, T.D.; Akert, R.M.; Sommers, S.R. Social Psychology, 9th ed.; Prentice Hall: Upper Saddle River, NJ, USA, 2016.

22. Deutsch, M.; Gerard, H.B. A study of normative and informational social influences upon individual judgement. J. Abnorm. Soc. Psychol. 1955, 51, 629-636. [CrossRef]

23. Hong, I.B. Understanding and Predicting Behavioral Intention to Adopt Mobile Banking: The Korean Experience. J. Glob. Inf. Manag. 2019, 27, 182-202. [CrossRef]

24. Sommestad, T. Social Groupings and Information Security Obedience within Organizations. In IFIP Advances in Information and Communication Technology, Proceedings of IFIP International Information Security and Privacy Conference, Hamburg, Germany, 26-28 May 2015; Springer Science and Business Media LLC: Berlin, Germany, 2015; pp. 325-338.

25. Hofstede, G.; Hofstede, G.J.; Minkov, M. Cultures and Organizations: Software of the Mind, 3rd ed.; McGraw-Hill: New York, NY, USA, 2010.

26. Cusumano, M.A. How traditional firms must compete in the sharing economy. Commun. ACM 2015, 58, 32-34. [CrossRef]

27. Valaei, N.; Rezaei, S.; Ismail, W.K.W.; Oh, Y.M. The effect of culture on attitude towards online advertising and online brands: Applying Hofstede's cultural factors to internet marketing. Int. J. Internet Mark. Advert. 2016, 10, 270-301. [CrossRef]

28. Hofstede, G. Cultures Consequences: International Differences in Work-Related Values; Sage: Thousand Oaks, CA, USA, 1980.

29. Farley, A.Y.D.; Murched, N. How Culture Moderates the Effect of Trust on Online Shopping Frequency. Master's Thesis, Malardalen University, Västerås, Sweden, 3 June 2016. Available online: https://www.diva-portal.org/smash/get/diva2: 946363/FULLTEXT01.pdf (accessed on 10 June 2016).

30. Kale, S.H.; Barnes, J.W. Understanding the Domain of Cross-National Buyer-Seller Interactions. J. Int. Bus. Stud. 1992, 23, 101-132. [CrossRef]

31. Naumov, A.; Puffer, S. Measuring Russian Culture using Hofstede's Dimensions. Appl. Psychol. 2000, 49, 709-718. [CrossRef]

32. Pizam, A.; Fleischer, A. The Relationship between Cultural Characteristics and Preference for Active vs. Passive Tourist Activities. J. Hosp. Leis. Mark. 2005, 12, 5-25. [CrossRef]

33. Sabiote, C.M.; Frías, D.M.; Castañeda, J.A. The moderating effect of uncertainty-avoidance on overall perceived value of a service purchased online. Internet Res. 2012, 22, 180-198. [CrossRef]

34. Al Kailani, M.; Kumar, R. Investigating Uncertainty Avoidance and Perceived Risk for Impacting Internet Buying: A Study in Three National Cultures. Int. J. Bus. Manag. 2011, 6, 76. [CrossRef]

35. Country Comparison. Available online: https://www.hofstede-insights.com/country-comparison/ (accessed on 10 June 2021).

36. Earley, P.C.; Gibson, C.B. Taking Stock in Our Progress on Individualism-Collectivism: 100 Years of Solidarity and Community. J. Manag. 1998, 24, 265-304. [CrossRef]

37. Akbar, P.; Mai, R.; Hoffmann, S. When do materialistic consumers join commercial sharing systems. J. Bus. Res. 2016, 69, 4215-4224. [CrossRef]

38. Wong, N.Y.C. Suppose you own the world and no one knows? Conspicuous consumption, materialism and self. Adv. Consum. Res. 1997, 24, 197-203.

39. Belk, R. Sharing. J. Consum. Res. 2010, 36, 715-734. [CrossRef]

40. Furner, C.P.; Racherla, P.; Zhu, Z. Cultural and review characteristics in the formation of trust in online product reviews: A multinational investigation. In Proceedings of the Wuhan International Conference on e-Business, Wuhan, China, 25 May 2013.

41. Xu-Priour, D.L.; Cliquet, G.; Palmer, A. The Influence of Buyers' Time Orientation on Online Shopping Behavior: A Typology. Int. J. Electron. Commer. 2017, 21, 299-333. [CrossRef]

42. Kim, D. Cognition-Based Versus Affect-Based Trust Determinants in E-Commerce: Cross-Cultural Comparison Study. In Proceedings of the International Conference on Information Systems, Las Vegas, NV, USA, 11-14 December 2005.

43. Schimmack, U.; Radhakrishnan, P.; Oishi, S.; Dzokoto, V.; Ahadi, S. Culture, personality, and subjective well-being: Integrating process models of life satisfaction. J. Personal. Soc. Psychol. 2002, 82, 582-593. [CrossRef]

44. Schimmack, U.; Diener, E. Affect intensity: Separating intensity and frequency in repeatedly measured affect. J. Personal. Soc. Psychol. 1997, 73, 1313-1329. [CrossRef]

45. Steenkamp, J.-B.E.; Geyskens, I. How Country Characteristics Affect the Perceived Value of Web Sites. J. Mark. 2006, 70, 136-150. [CrossRef]

46. Perfili, M.; Parente, S.; Grimaldi, M.; Morales-Alonso, G. A Study on Consumer Behaviour in the Sharing Economy. In Lecture Notes in Management and Industrial Engineering; Springer Science and Business Media LLC: Berlin, Germany, 2018 ; pp. 79-86.

47. John, N.A. The Social Logics of Sharing. Commun. Rev. 2013, 16, 113-131. [CrossRef]

48. Jaggar, A.M. Feminist Ethics. In Encyclopedia of Ethics; Garland Press: New York, NY, USA, 1992; pp. $363-364$.

49. Triandis, H.C.; Marin, G.; Lisansky, J.; Betancourt, H. Simpatía as a cultural script of Hispanics. J. Personal. Soc. Psychol. 1984, 47, 1363-1375. [CrossRef] 
50. Fiske, A.P. The four elementary forms of sociality: Framework for a unified theory of social relations. Psychol. Rev. 1992, 99, 689-723. [CrossRef] [PubMed]

51. Hofstede, G. Culture's Consequences Comparing Values, Behaviors, Institutions and Organizations across Nations; Sage: Southend Oaks, CA, USA, 2001.

52. Muñoz-Leiva, F.; Mayo-Muñoz, X.; de la Hoz-Correa, A. Adoption of homesharing platforms: A cross-cultural study. J. Hosp. Tour. Insights 2018, 1, 220-239. [CrossRef]

53. Hamari, J.; Sjöklint, M.; Ukkonen, A. The sharing economy: Why people participate in collaborative consumption. J. Assoc. Inf. Sci. Technol. 2016, 67, 2047-2059. [CrossRef]

54. Ryu, S.; Moon, C.W. Long-Term Orientation as A Determinant Of Relationship Quality Between Channel Members. Int. Bus. Econ. Res. J. (IBER) 2011, 8, 1-9. [CrossRef]

55. Bathaee, A. Culture Affects Consumer Behavior: Theoretical Reflections and an Illustrative Example with Germany and Iran. Available online: https:/ /ideas.repec.org/p/zbw / grewdp/022011.html (accessed on 1 February 2011).

56. Podsakoff, P.M.; Organ, D.W. Self-Reports in Organizational Research: Problems and Prospects. J. Manag. 1986, 12, 531-544. [CrossRef]

57. Yoo, B.; Donthu, N.; Lenartowicz, T. Measuring Hofstede's Five Dimensions of Cultural Values at the Individual Level: Development and Validation of CVSCALE. J. Int. Consum. Mark. 2011, 23, 193-210.

58. Diallo, M.F.; Mouelhi, N.B.D.; Gadekar, M.; Schill, M. CSR Actions, Brand Value, and Willingness to Pay a Premium Price for Luxury Brands: Does Long-Term Orientation Matter? J. Bus. Ethics 2021, 169, 241-260. [CrossRef]

59. Fishbein, M.; Ajzen, I. Belief, Attitude, Intention, and Behavior: An. Introduction to Theory and Research; Adison-Wesley: Reading, MA, USA, 1975. [CrossRef]

60. Davis, F.D. Perceived usefulness, perceived ease of use, and user acceptance of information technology. MIS Q. 1989, 13, 319-340. [CrossRef]

61. Kline, R.B. Principles and Practice of Structural Equation Modeling, 3rd ed.; The Guilford Press: New York, NY, USA, 2011.

62. Nunnally, J.C. Psychometric Theory; McGraw-Hill: New York, NY, USA, 1978.

63. Anderson, J.C.; Gerbing, D.W. Structural equation modeling in practice: A review and recommended two-step approach. Psychol. Bull. 1988, 103, 411-423. [CrossRef]

64. Hair, J.F., Jr.; Black, B.; Babin, B.J.; Anderson, R.E. Multivariate Data Analysis, 7th ed.; Pearson: London, UK, 2010.

65. Fornell, C.R.; Larcker, D.F. Evaluating structural equation models with unobservable variables and measurement error. J. Mark. Res. 1981, 18, 39-50. [CrossRef]

66. Kumar, V.; Lahiri, A.; Dogan, O.B. A strategic framework for a profitable business model in the sharing economy. Ind. Mark. Manag. 2018, 69, 147-160. [CrossRef]

67. Vandello, J.A.; Cohen, D. Patterns of individualism and collectivism across the United States. J. Personal. Soc. Psychol. 1999, 77, 279-292. [CrossRef] 